\title{
LE PIDIERON A LA CIUDAD MÁS DE LO QUE PODÍA OFRECER: POLÍTICAS SEXUALES Y CONFLICTO EN LA REGIÓN CARIBE
}

\author{
THEY ASKED THE CITY MORE THAN IT COULD OFFER: \\ SEXUAL POLITICS AND CONFLICT IN THE CARIBBEAN REGION
}

Por: José Fernando Serrano Amaya

pólogo, UniversiJacional de Colom 994), MA Conflict

ution, University

adford (2004). Se esempeñado en la

tigación forma

y coordinación de

ectos en áreas so-

, particularmente

solución de conflic-

lerechos humanos

istrucción de paz

na perspectiva an-

lógica, cultural, de

o y generación. Ha

ado en organizacio-

ciales y educativas

nales, multilaterales

ooperación interna

1. Ha sido docente d

iversidades Central

iana, de los Andes y

nal, en Colombia, y

ng Fellow en la Uni-

lad de Sussex, y en

iversidad de South

(UK). Jser1926@

ydney.edu.au

Recibido: 4 febrero de 2015 - Aprobado: 10 de abril de 2015

\begin{abstract}
RESUMEN
Este texto explora los modos en que las violencias relacionadas con la orientación sexual o la identidad de género interactúan y se construyen mutuamente con las violencias de los conflictos armados. Se argumenta que tales violencias hacen parte de la redefinición del contrato social en procesos de transición política que va a la par de una redefinición del contrato sexual de la nación. Para ello se explora la historia de vida de una joven costeña y como desde diferentes aspectos de su vida ha experimentado las interacciones entre las violencias sociopolíticas que vive el país y la región y las violencias relacionadas con el género y la orientación sexual. La historia problematiza clasificaciones categóricas de las violencias y demandan derechos por separado y las categorías fijas de sujetos definidas desde una condición de vulnerabilidad. Permite además ilustrar como en las transiciones entre los conflictos unas formas de violencia se transmutan y recomponen manteniendo para algunos sectores sociales el ser objeto permanente de violencia. Lo anterior en las contradicciones generadas en un contexto de apertura económica y de promoción de la región Caribe como polo de turismo nacional e internacional que permite ciertos cambios pero impide otros.
\end{abstract}

Palabras claves: Homofobia, violencia, género, sexualidad, conflicto.

\begin{abstract}
The article explores the interactions between violences based on gender identity, sexual orientation and armed conflict. It argues that those violences are part of the redefinition of the social contract during political transitions that requires also a redefinition of the sexual contract of the nation. The life story of a young woman is used to illustrate the how the political conflict in Colombia and in the Caribbean region affects gender and sexual orientation violence. The example challenges categorical classifications of violence, rights claims and notions of vulnerability and identity. It also shows how reshape during the conflict transitions and keep some social subjects at permanent risk of violence. The article locates this discussion in the current economic trends in the Colombian Caribbean lands, where tourism and the new markets facilitate some changes and impede others.
\end{abstract}

Keywords: Homophobia, violence, gender, sexuality, conflict.

'Yo le digo a mi novia todos los días, no hay nada más triste que si a mí me pegan un tiro todo el mundo a va decir "es que ellas se lo buscaron", porque pidieron más de lo que la ciudad podía ofrecerles' Lena, Costa Caribe, Colombia 


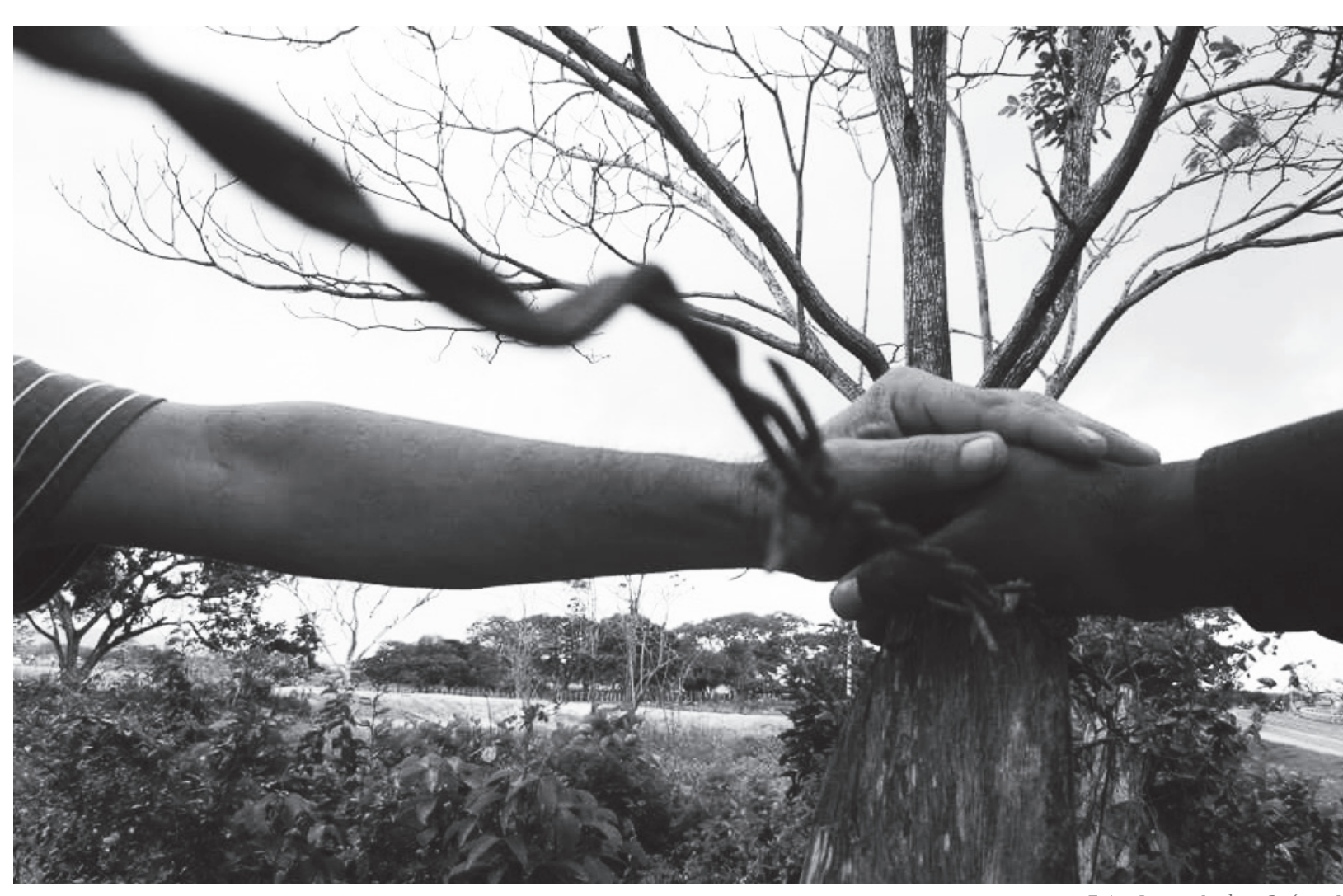

\section{Introducción}

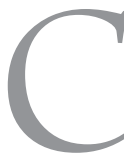

Y on la anterior frase terminaba una de las entrevistas realizadas para esta investigación ${ }^{1}$, cuyo objetivo ha sido la exploración de los usos de la violencia 'homofóbica' en contextos de conflicto armado. El concepto de 'homofobia' ha sido significativo para articular movilizaciones sociales en torno a temas de orientaciones sexuales e identidades de género. Ha sido fundamental para dar nombre a formas de violencia invisibilizadas o legitimadas social, política y culturalmente. Sin embargo, desde sus inicios ha sido también un concepto debatido, contestado y ha pasado por múltiples revisiones. La exploración de las formas como las relaciones de género y sexualidad producen exclusiones, discriminaciones, jerarquías, prejuicios, muestra que se trata de fenómenos múltiples y en interacción con diferentes estructuras sociales. Sin embargo, es una exploración que se ha hecho sobre todo en contextos de no-guerra y desde paradigmas del Norte global. Explorar los modos en que las violencias relacionadas con la orientación sexual o la identidad de género interactúan y se construyen mutuamente con las violencias de los conflictos armados, requiere considerar continuidades, cambios y novedades en los ordenamientos del genero y la sexualidad como en las dinámicas de las violencias. En particular cuando actores armados distribuyen riesgos y protecciones, reproducen prejuicios y se lucran de ello.
${ }^{1}$ Este artículo se en información gida para la tesis
toral Gender, sexu and violence in po da por el autor Universidad de Sy Australia (2011-2 dirigida por la prof Raewyn Connell, y realizada grac Postgraduate res scholarship - au lian postgraduate a otorgada por la m entidad y el gob
australiano. La tes australiano. La tes
plora los usos de encia anti-homos y contra personas en conflictos arma sus cambios en las
siciones a la democ tomando como dios de caso Sur y Colombia. Para realizaron entrevis vos históricos e respectivos paíse información que s en este artículo vie entrevistas realizac Barranquilla y C gena entre enero y de 2013. Por mo de seguridad de la sonas entrevistad nombres han sido biados y se han on referencias que fac
su identificación. I ción de '(para) po sexuales es una elaborada en la sión y conclusion dicha tesis. 
Más aún cuando redefinir un nuevo contrato social mediante la violencia, implica recrear el contrato sexual de la nación, también con violencia (Das, 2007, p. 19).

Este texto contribuye a tal debate desde un caso particular. La historia de una joven costeña y como desde diferentes aspectos de su vida ha experimentado las interacciones entre las violencias sociopolíticas que vive el país y la región y las violencias relacionadas con el género y la orientación sexual. La historia que Lena compartió para esta investigación pone en escena la forma como diferentes formas de violencia se hacen cotidianas, se integran a los planes vitales y se corporizan. Permite además observar lo que puede significar la experiencia de los conflictos o las guerras para aquellos que sin ser víctimas directas viven también las consecuencias y efectos de los conflictos. Abordada desde una mirada antropológica, la historia permite observar los límites de las formas como se entiende la experiencia de las violencias y sugiere otros aspectos a considerar. Se trata de una historia particular y sin pretensiones generalizantes. Sin embargo, permite construir conocimiento desde las experiencias de personas ubicadas en situaciones concretas y en momentos específicos.

\section{Breve nota sobre método}

- as narrativas elaboradas para esta investigación se basaron en una perspectiva de historia oral en la cual se enfatizaban aspectos de J memoria e historias colectivas. Las narrativas de historia oral han sido cuestionadas por la ilusión de transparencia que pueden generar. Más aun, pueden perpetuar una autoridad académica al sustentarse en la conexión entre el sentido de propiedad de quien cuenta y la presunción de autenticidad en la narración (Kim, 2008). Testimonios de quienes han pasado por vivencias de guerra y violencia son a veces cuestionados en términos de la 'realidad' que relatan o de la autoridad de quien habla. Un ejemplo de esto, fue el debate generado por la publicación del libro de la Premio Nobel de Paz, Rigoberta Menchú sobre sus experiencias en la guerra en Guatemala (Beverly, 2000). El texto fue cuestionado por falta de precisión y por generar imágenes erradas del conflicto.

Esta investigación parte de una perspectiva diferente. Investigadoras feministas (Haug, 1987) y queer (Epprecht, 2004) han usado las historias orales no como forma de 'recoger información' o de reproducir una 'realidad' sino como un proceso de encuentro, expresión, reflexividad y sentido colectivo. En este 
caso, las personas participantes se abordaron como expertas productoras de conocimiento. Un conocimiento que surge tanto de su experiencia como de su práctica para transformar las violencias que han vivido.

\section{'Me ha tocado ganarme que me reconozcan como costeña': sentidos de pertenencia y no-pertenencia}

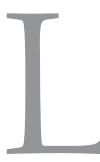

ena es una joven profesional. Actualmente vive con su novia en una ciudad de la costa Caribe. Aunque en este momento vive una relación con otra mujer, se define como bisexual. Lena nació en Medellín en 1987. Siendo aun muy pequeña, su familia migró a la costa para montar un pequeño negocio. A pesar de haber crecido y vivido toda la vida en el Caribe, ella siempre ha sido percibida como 'cachaca'. Su color de piel, su modo de hablar y vestirse y el no tener una red familiar extensa en la zona son aspectos mencionados con frecuencia para marcar tal diferencia. Ante eso, Lena reacciona nombrando los lugares que conoce, las personas que son sus amigas, las expresiones locales. Incluso cuando me contaba esto, su tono de voz cambiaba, enfatizando el acento del lugar.

La conversación con Lena inició en ejercicio de identificación de experiencias de violencia relacionadas con la orientación sexual. Al inicio, Lena compartió una historia que operó como hilo conductor de la entrevista. Un día, mientras estaba en un bar frecuentado por jóvenes de la ciudad y turistas, ella y su novia se dieron un beso. Por ello, se les pidió que dejaran el lugar. Tal evento generó una serie de debates. Por una parte, quienes les apoyaban hacían un llamado a que tales sitios fueran más 'respetuosos'. Por otra, quienes estaban del lado del dueño del lugar y el mismo, consideraban que los heterosexuales también tenían derecho a ser 'respetados' y que la ciudad no estaba preparada para ese tipo de manifestaciones. El hecho de ser ellas de la región salió a relucir como parte de lo que hacia la diferencia en el manejo del tema, pues de ser extranjeras, como una parte de quienes asisten al lugar, el asunto habría sido diferente. Dicha posición fue incluso apoyada por un conocido, que si bien es homosexual y crítico de las actitudes que se tienen en la región Caribe con respecto al tema, consideraba que 'se les había ido la mano' besándose en público.

En estudios de identidades sexuales esta es una historia frecuente. Ilustra la forma como el asumir una orientación sexual no normativa se vuelve evento crítico para la persona, su familia y su entorno particular. Sin embargo, el contexto y momento en que se da le hacen particular. La historia que Lena 
compartió no es tan solo una historia más de la crisis que genera la 'salida del closet'. Por el contrario, ilustra la forma como diversas formas de violencia se conectan entre sí en una región que vive acelerados procesos de cambio para ajustarse a las demandas de una economía de mercado que le impone una modernización acelerada.

\section{Empacando y desempacando la 'violencia' y el 'conflicto'}

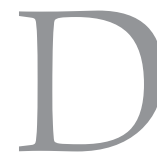

esde una perspectiva de activismo, la historia que compartió Lena inicialmente, puede interpretarse como un acto de discriminación o de 'lesbofobia'. En efecto, se podría argumentar incluso legalmente, que se les restringió un derecho fundamental. Varios de los logros de lo que hoy se engloba como 'derechos LGBT' están asociados a ese derecho al espacio público. Al recordar el evento, Lena no lo relató en clave de derechos vulnerados sino como un evento que desencadenó el que ella y su novia deciden 'asumirse' de manera más explícita como pareja. Ello no quiere decir que desconociera el daño causado por tal evento. Luego en la entrevista Lena recordó como ese evento se conecta con otros eventos más, como los insultos que a veces escuchan en la calle, las amenazas por parte de actores armados ilegales o el saber que se vive en una sociedad en la cual algo tan sencillo como tomarse de la mano de su novia es visto como ofensivo y merecedor de una violencia justificada social y culturalmente. En su narrativa, las violencias no están separadas en tipologías como se hace en las clasificaciones legales, criminológicas o políticas. Tampoco en la forma como hacen las políticas de la identidad para definir unos sujetos como 'discriminados históricamente' y por ende merecedores de 'reconocimiento'. En su narrativa Lena no separó lo sucedido en el bar como un acto de 'homofobia' de las otras violencias que vive como mujer, como joven o como activista estudiantil. Su narrativa desbordó el marco mismo de la investigación que motivó la entrevista pues en su caso las violencias relacionadas con el conflicto armado o las violencias relacionadas con la orientación sexual no operan como entidades diferenciables o unificadas, y por ende, susceptibles de ser diseccionadas y tratadas por separado. Por el contrario, se trata de conglomerados y ensamblajes de modos en los cuales determinados actores de la sociedad en que vive ejercen sufrimiento y dolor. Un ejercicio que a veces está legitimado y justificado social, política y culturalmente.

Desde una perspectiva antropológica y cultural, inscribir un evento como 'violencia' o resultado del 'conflicto', requiere considerar los ejercicios mediante los cuales unos eventos y no otros se definen como 'violentos'. En una serie 
de estudios sobre el sufrimiento social, Kleinman, Das y Lock (1997) afirman que la violencia no es una experiencia evidente en si misma sino el resultado de complejos procesos de narración, representación y subjetividad. Procesos que resultan de interacciones sociales y que varían de acuerdo con una serie de condiciones estructurales e históricas. Con ello, no se trivializa el sufrimiento causado sino por el contrario se lo ubica en los contextos que lo hacen una experiencia vivida, susceptible de ser narrada y transformada pero también de ser ignorada, olvidada o suprimida.

Al respecto, las políticas del conocimiento que permean tanto la producción académica como jurídica sobre la violencia y sus transformaciones hacen significativos esfuerzos por visibilizar y evidenciar la complejidad de las formas de victimización y de los daños causados por las guerras y los conflictos. En el caso colombiano, por ejemplo una producción reciente ha mostrado la dimensiones de género, de etnia o de generación que ha tenido el conflicto. Marcos legales han establecido fechas, definiciones y mecanismos para compensar daños. Estos ejercicios sin embargo, generan debates con respecto a qué se incluye y qué no, de qué modo se definen unas victimas y no otros, o que violencias se compensan. El caso surafricano ha sido emblemático en ello. La definición de gross violations of human rights - violaciones atroces de los derechos humanos usada durante la Comisión de la Verdad implicaba una nocion de 'violencia política' que dejó de lado una serie crímenes también relacionados con el apartheid, como la violencia sexual y de género (Antjie \& Nosisi, 2009).

Al respecto, Carolyn Nordstrom (1999) llama 'políticas del no-saber' a las acciones que hacen que una sociedad no vea ciertos asuntos relacionados con la violencia y la guerra. Ella usa concepto para llamar la atención sobre la situación de las mujeres jóvenes y en particular de las niñas en zonas de guerra, las cuales son por una parte las mas explotadas, victimizadas y sin posibilidades de defensa y por otra las mas invisibles. Tales políticas del 'no-saber' no solo son sobre su situación sino sobre las industrias que las explotan y se lucran de ellas y por lo tanto facilitan su permanencia. Como se mencionará más adelante, tales políticas de 'no saber' pueden ir a la par de la existencia de información. La violencia contra homosexuales, lesbianas, bisexuales y transgeneristas en contextos de conflicto sociopolítico viene siendo denunciada en Colombia desde inicios de los noventa y solo recientemente se la empieza a considerar.

En este sentido, al momento en que Lena habla de 'la violencia' o 'el conflicto' no solo está hablando de eventos que conoce, ha vivido e incluso estudiado. 
Habla también de cómo esos eventos se hacen parte de su historia personal. 'El conflicto' aparece en la historia de Lena en varios momentos y como marcador de momentos vitales significativos en su historia. Ella pasó su adolescencia en los primeros años de la década pasada, cuando su ciudad y la región vivían la creciente presencia del paramilitarismo. En ese tiempo, dos de sus amigos fueron muertos por ser pelucones, esa extraña asociación entre tener el cabello largo, escuchar rock, ser estudiante universitario y tener ideas revolucionarias, que hacía peligrosa la condición juvenil misma. Cuando Lena era joven, ser joven era peligroso. Lena recuerda que durante ese tiempo mientras un sector de la ciudad viva con la idea de 'seguridad' o 'tranquilidad' impuesta por actores armados ilegales, otro sector vive con zozobra y bajo amenaza y sospecha constante. Fue el tiempo de las 'limpiezas', cuando actores armados persiguieron sectores sociales discriminados como forma de obtener legitimidad para sus acciones. Con la cotidianización de la violencia, esta también se hace experiencia corporal. Lena mencionó como a veces el oír una moto detrás de ella en la calle la hace mirar atrás con preocupación o la hace despertarse asustada si sucede estando en su casa. La imagen del sicario motorizado ha sido producida y reproducida de tal modo que pareciera generar respuestas como estas.

La historia que Lena compartió introduce la pregunta de cómo 'la violencia' y el 'conflicto' se hacen vivencias cotidianas y se incorporan en las historias de vida de quienes aunque no han vivido en las zonas de guerra tienen una experiencia de ella. Aquí también tal diferencia se hace problemática. Lena ha pasado la mayor parte de su vida en una ciudad capital de la costa Caribe. La posibilidad de haber llegado a la educación universitaria implica unas condiciones que muy posiblemente quienes han vivido en las zonas rurales donde se vive la guerra a diario no han tenido. Sin embargo, la 'violencia' o el 'conflicto' no le son una realidad ajena o distante. Como ella señaló a todo lo largo de la entrevista tienen efectos directos en su vida cotidiana, en su vivencia de género, en su sexualidad. Un elemento constante en su narración es la incertidumbre. No saber quien lo puede estar mirando a uno, la posibilidad que algún momento le ataquen, fueron referencias frecuentes y asociadas a cosas como su vida estudiantil o su relación de pareja.

Suponer que las violencias vividas en lo rural no han afectado lo urbano es desconocer entre otros eventos, la forma como el desplazamiento por causa del conflicto ha redefinido la vida en las ciudades colombianas. Más aun en las ciudades capitales de la costa Caribe que han sido receptoras de importantes 
sectores de población desplazada. Lena vive en una ciudad que ha sido redibujada por el desplazamiento y que a la vez se presenta al resto del país y al exterior como si este no le hubiera tocado. Clasificar su experiencia de la violencia entre 'directa' e 'indirecta', resulta simple y limitado.

En una etnografía sobre la vida cotidiana durante la guerra en Croacia, Maja Frykman (1997) se pregunta de cómo vivían el conflicto aquellos sectores de población que, si bien estuvieron expuestos a control militar, privaciones y peligros, por diferentes razones ni se desplazaron, ni se refugiaron ni tuvieron pérdidas irreparables. Los que llama metafóricamente 'la mayoría olvidada', dado lo poco que se mencionan sus vivencias (M. Frykman, 2008). Lo que encuentra son una serie de 'estrategias de sobrevivencia' que buscan restablecer o crear un mínimo sentido de 'normalidad' manteniendo rutinas diarias y que con frecuencia están ancladas a las vivencias de lugares concretos: la casa, una tienda, una plaza. Pertenecer al lugar, situar la identidad en un espacio concreto, se vuelven modos de crear una mínima cotidianidad ante los efectos destructores de devastadores de la guerra. Algo de 'normalidad' es lo que se añora cuando la guerra es experiencia cotidiana.

\section{Desmovilizar ejércitos no desmoviliza miedos}

7 la pregunta por qué la ha hecho sentirse vulnerable y posible víctima de violencia, Lena respondió la 'renovación del conflicto' en la región. Con 'renovación del conflicto' Lena se refería a las oleadas de amenazas mediante panfletos que han circulado en la zona Caribe en los últimos años dirigidas contra colectivos y personas calificadas como 'indeseables': usuarios de drogas, trabajadoras sexuales, homosexuales y lesbianas, principalmente. Al hablar de la 'renovación', Lena reiteraba la presencia en sus memorias de un evento anterior y establecía una marca temporal diferente a las cronologías oficiales del conflicto y el post-conflicto.

La referencia que hace Lena a la mal llamada 'limpieza social' se ancla en una larga historia de presencia del tema en las experiencias y memorias de la violencia en Colombia, en la estigmatización de la marginalidad y en la forma como ello se incorpora en la percepción de vulnerabilidad en ciertos sectores sociales. Ejecuciones extrajudiciales cometidas por actores institucionales y para-institucionales contra sectores sociales marginalizados han sido registradas en Colombia al menos desde los años ochenta y en varias regiones del país (Rojas, 1994). Indigentes, jóvenes en situación de calle, trabajadoras sexuales, homosexuales en situación de pobreza o travestis han sido algunos 
datos que se menn vienen de una on de los informes sticia y paz y noche bla producidos por misión Interconacional de Justicia z y por el Centro vestigación y Edun Popular - Cinep visión cubrió todo umeros publica reros publicados nbre de 2010.

los objetivos de la tigación, la inforon relacionada con lazas colectivas se zó desde la perspecetemas de género lidad. 'Homosexua s el termino más para describir la para describir la tas. El término $\mathrm{s}$ en 25 de los casos rrados. 'Lesbianas contró en 8 casos cas' en 6, 'travestis 'bisexuales' en 4 unidad LGBT' en 4 referencias no so yentes entre sí. Por lo, en 6 casos ionan onuales'. D do con entrevista adas, la informacontenida en los in es de Noche y Niebla nsignada de mod al como aparec fuente. Es posible mbargo que en e so de documenta licar los casos, po lo en la prensa na se usen término seráno con correctos. Con ell urían estar borrand ncias que son signivas para el análisi por ejemplo, s lectivo nombrado perpetrador es pestis' en es . omosexuales'. Po olo, de las 20 vícs de 'limpieza soentre 1992 y 1994 ificadas en el infor ionero de Ordóñe 6), nueve teníar de nombre Si bien de m. Sín bien de ta mación no se pued cir directamente la idad de género de ctimas, si da pista - las interacciones género y sexuali los patrones nización. atención internacional desde los primeros años de los noventa. En 1994 un informe del Relator Especial sobre Tortura y Ejecuciones Extrajudiciales mencionaba la acción de grupos de 'limpieza social' contra 'homosexuales' y llamaba la atención sobre la legitimidad, impunidad y complicidad de algunas autoridades con los hechos. Dos años después Juan Pablo Ordoñez (1996) publicó uno de los primeros informes en que se exploraban los temas de orientación sexual en relación con las ejecuciones extrajudiciales. Una larga historia de documentación del tema va a la par de una larga historia de falta de acción estatal al respecto.

Con respecto a la circulación de panfletos amenazantes, información recogida para esta investigación encuentra que el uso de de grafitis, avisos pegados en postes y volantes en los que se amenazan colectivos marginalizados o discriminados se puede datar al menos a la segunda parte de la década de los noventa ${ }^{2} .347$ de este tipo de amenazas se identificaron entre el 1 de enero de 1998 y en 12 de diciembre de 2010. Los contenidos de las mismas varían de acuerdo con la intención del actor armado. En unos se alerta de tales ejecuciones; en otros se informa a las víctimas que están bajo vigilancia; en otros más, se dan razones por las cuales se cometieron los hechos. La revisión de los mismos encuentra un desarrollo progresivo tanto en el tipo de víctimas que se incluyen como en el grado de especificidad del nombramiento. De panfletos en los que se menciona uno o dos colectivos se pasa a otros que incluyen más categorías de sectores sociales y de panfletos dirigidos al colectivo en general se pasa a panfletos en los que se dan nombres, apodos y direcciones de las posibles víctimas.

En 39 de los 347 casos identificados se hacen referencias directas a orientación sexual o identidad de género como razón de vulneración y amenaza ${ }^{3}$. En 33 de tales casos, las amenazas contra 'homosexuales', 'lesbianas', 'travestis', 'bisexuales' o 'comunidad LGBT' van a la par de amenazas contra otros colectivos. La orientación sexual o la identidad de género no aparece como un elemento aislado de amenaza sino en su asociación con un conjunto de comportamientos y sectores sociales marginalizados. La asociación más común es entre 'homosexuales' y 'prostitutas', la cual aparece en 23 de los casos identificados, seguida de la asociación con vendedores o consumidores de drogas, que aparece en 16 y 11 casos, respectivamente. La asociación con 'ladrones' aparece en 13 casos. En 20 de los 39 casos, las amenazas relacionadas con la identidad de género o la orientación sexual van asociadas a amenazas a 'prostitutas', 'ladrones' y 'drogadictos'. El resultado de estas asociaciones 
en el caso de Lena es una especie de contabilidad de la vulnerabilidad, pues ella puede ser clasificada en varias de tales categorías.

Lo que Lena llama 'la renovación del conflicto', después del proceso de desmovilización de los paramilitares coincide también con la información encontrada en las amenazas colectivas y en información brindada por personas entrevistadas en Santa Marta, Montería o Cartagena. 28 de las 39 amenazas en las cuales se menciona la orientación sexual o la identidad de género aparecen asociadas a la acción de grupo paramilitares. En un caso un Frente del ELN usó amenazas similares, en otros miembros de la policía, mientras el resto son asociados a 'grupos de intolerancia'. 5 de las amenazas asociadas a grupos paramilitares ocurrieron en 2002, antes del inicio del proceso de desmovilización de los grupos pertenecientes a las Autodefensas Unidas de Colombia - AUC. Cuatro de ellas ocurrieron en la región Caribe. La dos primeras amenaza identificadas en donde se menciona explícitamente a 'homosexuales' fueron hechas en Ovejas, Sucre, y Ciénaga de Oro, Córdoba, por parte del grupo paramilitar Héroes de Montes de María. Esta información coincide con lo que ha sido llamado la 'Ruta del terror' de expansión del paramilitarismo en el Caribe (CNRR, 2011).

Entre 2002 y 2007 las amenazas contra 'homosexuales' se concentraron en el norte del país y después de 2008 se extendieron a otras regiones de Colombia. La mayor parte de las amenazas identificadas en las que aparecen temas de orientación sexual o identidad de género ocurrieron entre 2009 y 2010 (28), cuando los grupos asociados a las AUC estaban formalmente desmovilizados y las llamadas Bandas Criminales Emergentes estaban actuando. De comprobarse un mayor incremento en la violencia 'homofóbica' luego de la desmovilización de un grupo armado, ello no sería inusual. Estudios sobre violencia sexual y de género, y violencias contra homosexuales, lesbianas, bisexuales o transgeneristas encuentran que tales violencias no necesariamente desaparecen con los postconflictos sino que se pueden reforzar o reconfigurar (Di Silvio, 2011; Pankhurst, 2008). Lo anterior tampoco niega los usos que un grupo armado ilegal pueda hacer de la violencia 'homofobica' como parte de sus estrategias de guerra. Lo que esta información sugiere, es que grupos con diversas características pueden hacer uso de tales formas de violencia para diferentes fines.

El impacto de los panfletos en los cuales se amenazaba por la orientación sexual o la identidad de género fue tema de conversación con las personas que participaron de esta investigación. Al menos tres de tales impactos pueden diferenciarse, de acuerdo con los relatos obtenidos. 
Los panfletos tienen un sentido de amenaza directa contra unos grupos en particular. Les advierten de la vigilancia que se ejerce sobre ellos. Como se mencionó antes, a los panfletos que circularon en 2002 le siguió el asesinato de tres hombres homosexuales en Soledad, Atlántico por el Frente 14 Unido de Soledad. Referencias a homosexuales, lesbianas y travestis que se fueron de sus lugares de residencia por esa época también fueron recogidas en la investigación. En ese sentido, el panfleto es confirmado con un hecho concreto que demuestra su efectividad.

Participantes de la investigación en diversas ciudades compartieron que una vez los panfletos circulan, quienes pertenecen a los colectivos nombrados dejan de ir a sus sitios de encuentro habituales. Gays dejan de ir a la playa luego de la rumba o de reunirse en el sitio predilecto para socializar, travestis en prostitución dejan sus sitios de trabajo. Como cuenta Lena, una vez los panfletos han circulado el movimiento por la ciudad se restringe. En un sentido, el panfleto emplaza. En otro sentido, como también recordaron los mismos participantes, el panfleto desplaza. Tal es el caso de mujeres trans que ante las amenazas van a otros lugares, como se ha encontrado ya en otras investigaciones (Prada, Galvis, Lozano, \& Ortiz, 2012) y se confirmó en este trabajo. El panfleto entonces recuerda y reitera condiciones previas de discriminación y violencia.

En tercer lugar, el panfleto tiene un sentido 'simbólico', como mencionó Lena. Con ellos, se llama a un cierto orden ético y moral. Ya que a veces son anónimos o hablan en general en nombre de la 'comunidad', hacen pensar que se trata de un sentir general. Al advertir o anunciar, pero sin tener claridad si en efecto puede pasar o no, los panfletos crean unas ciertas 'zonas grises' o de incertidumbre. Su reciclaje, repetición y reproducción en oleadas hace pensar que la amenaza está todo el tiempo y en todo lado, confirmaron participantes de otras zonas.

El que los panfletos circulen en espacios públicos, el que sean hechos para ser repetidos y multiplicados, a veces sin clara conexión de tiempo o espacio pues no siempre tienen fecha o lugar, les asimila también a otros mecanismos de control social como el rumor. En un estudio sobre el asesinato de Indira Gandhi, Veena Das (Das, 2007) argumenta como el rumor actualiza ciertos eventos del pasado y crea un sentido de continuidad entre ellos que de otro modo no sería posible lograr. La traducción de estas memorias en acción, sin embargo, depende de una serie de factores propios al contexto en que se dan los hechos violentos (Das, 2007, p. 109). La creciente incorporación de categorías 
y sujetos incluidos en las amenazas producidas en los panfletos puede verse una forma de tal actualización. Su rotación y translación hace pensar no solo en quienes lo usan y ponen en circulación sino en quienes no están incluidos allí. La amenaza a un grupo particular, a la vez que le construye como fuente de miedo, define a la 'comunidad' como vulnerable y necesitada de protección. Al producir y actualizar a unos como peligrosos, se reitera la inseguridad que otros, la 'comunidad', vive. El panfleto produce, reproduce y exacerba la sensación de 'anormalidad' creada por el conflicto. El panfleto hace rentable el deseo de 'normalidad' vivido en un contexto de guerra y donde la violencia es cotidiana garantiza el espacio para un proyecto de protección militarista y masculino, y para una industria privada de la seguridad.

\section{Ordenamientos del género y la sexualidad en interacción}

lexplicar las implicaciones de asumir una relación de pareja lesbiana
en la región Caribe, Lena hizo evidente la interacción entre diferentes
órdenes raciales, sexuales y de género ${ }^{4}$. Uno, el que ella vive y otro el de su novia. La familia cercana de Lena está compuesta principalmente por mujeres. Cuando su relación de pareja se hizo evidente, la primera reacción de la madre de Lena fue por su seguridad no por el tipo de relación. Con frecuencia, ella le recuerda a Lena que 'estén pilas en la calle', 'no se cojan de la mano en público' 'ojo a lo que ponen en Facebook'. Cuando Lena y su novia decidieron irse a vivir juntas, estuvieron en la casa de Lena por varios meses. La migración laboral, la autonomía femenina, la relación de distancia tanto con el contexto de origen como con el entorno, abren espacios para relaciones de género más flexibles.

En el caso de la familia de su novia, las redes familiares, la pertenencia al contexto y la movilidad social, definen otros ordenamientos de género. Esta familia llegó a la ciudad desplazada de otra región de la costa y viven ahora en una zona fuertemente unida por redes culturales, de clase y de solidaridad. Para ellos, una hija lesbiana no es solo vergüenza sino impedimento para las posibilidades de ascenso social que dependen de las relaciones de solidaridad con otros similares. El 'qué dirán' no es solo control social sino también mecanismo de pertenencia y garantía de apoyo. A Lena su condición de no-costeña le impide participar en las redes de solidaridad locales asociadas a las relaciones familiares pero le da un espacio para renegociar relaciones íntimas. Para su novia, su condición de costeña le ha permitido un sentido de pertenencia pero le dificulta proponer modelos alternativos de pareja. 
A pesar de estas diferencias, Lena señaló que las consecuencias de asumir una relación lésbica eran similares. Tales similitudes vienen en parte de la permanencia de dos de los hitos que siguen definiendo el transito a la vida adulta: trabajo y vida en pareja (Smelser \& erikson, 1980). Las dos pasaron de ser estudiantes apoyadas por sus familias a ser 'mujeres independientes' buscando el modo de acceso al mundo laboral. 'Meseriar' o trabajar en bares fue una de las cosas que ellas hicieron y es una de las opciones laborales que se ofrecen a jóvenes estudiantes en una región que cada vez mas depende del turismo. Dado que el acceso al mundo laboral dentro de un escenario legal, si bien no está garantizado por la educación, depende de ella, las dos han seguido como han podido sus estudios. Pero además, el acceso laboral depende de una heterosexualidad asumida o presumida. Lena señaló también como en sus respectivos trabajos mantienen una imagen de mujeres heterosexuales o al menos, evitan cualquier indicio que aluda a su relación de pareja. Mas ahora que una de ellas trabaja para una ONG de corte religioso que ofrece servicios sociales. Como el turismo, la industria de la reparación social también prolifera en la región y demanda profesionales especializados. Además, esto les implicó dejar su compromiso político como estudiantes universitarias. Tal compromiso fue visto por la familia de la novia de Lena como parte de lo que la hizo 'descarriarse' y es además un factor de riesgo en un escenario donde la movilización estudiantil está estigmatizada. El resultado de estas decisiones fue resumido con la frase de Lena 'ya nos ven como dos peladas serias que asumieron una situación como pudieron'. Por eso, la necesidad de tener una casa propia y hacer evidente que 'a pesar de todo', han 'progresado'. El 'progreso', finalmente, sigue siendo marcador del tránsito a la vida adulta en contextos marcados por el riesgo de pauperización, la fragilidad económica y las limitadas opciones de movilidad social (Serrano-Amaya, 2004).

\section{Evitar el exceso, mantener el orden}

T a descripción que hace Lena de su tránsito a la vida adulta, en parte forzado por la decisión de asumir una relación de pareja lésbica, tiene unas connotaciones que requieren ser leídas en el contexto de conflicto que vive la región. Ya se discutió antes como el recurso que actores armados ilegales han hecho de las ejecuciones extrajudiciales y las amenazas contra sectores sociales y comportamientos considerados como 'desviados' han impactado en su percepción de seguridad y en su vida cotidiana. Lena ejemplificaba el volverse 'peladas serias' como resultado de asumir su relación de pareja y con la forma como regulan su vida domestica en un contexto donde la preocupación constante por el 'qué dirán' se combina con el 'uno no 
sabe quien lo está mirando', como decía ella. En otras palabras donde formas tradicionales de reconocimiento social basadas en el respeto, el honor o la 'decencia' se combinan con los mecanismos de control usados por los actores armados. En su vecindario, por ejemplo, ellas procuran que su casa se vea bien mantenida y en orden pues cualquier signo de 'desorden' puede llamar la atención sobre ellas. Por ejemplo, evitan ser vistas tomando o fumando y cualquier signo que puedan estarse 'chirretiando', como explicaba Lena.

Esta noción del 'chirrete' resulta sugestiva para explorar formas de jerarquización social. Chirretiarse es un término asociado al descuido, al estar mal vestido, a consumir droga en exceso. Su origen es asociado al parlache, ese lenguaje asociado a jóvenes de sectores populares de Medellín y luego popularizado por medios de comunicación. En el relato de Lena, si el chirretiarse alude a un desorden, su contrario, como también lo explicaba ella es el 'andar derechito', 'no desviarse'. Explorando en la entrevista quienes podrían ser vistos en riesgo de 'chirretiarse' Lena mencionó tres categorías más de sujetos sociales: los que usan demasiada droga y hacen evidente su estado; los que organizan protestas y por ende causan desorden; los pelucones, esos hombres jóvenes que por su vestuario e ideas 'revolucionarias' son vistos como menos masculinos. En el caso de Lena y su pareja, 'chirretiarse' serían las expresiones públicas de afecto. En esta idea hay dos elementos: uno, el chirretiarse es pasar un límite. Otra, el 'chirretiarse' implica hacer público algo que debería mantenerse privado. Como decía Lena, si se usan drogas pero se hace en privado y se mantiene una vida productiva, no hay riesgo de 'chirretiarse'.

La idea de 'exceso' implícita en esta argumentación es útil aquí para discutir lo que Lena menciona. Elsa Blair (2005) usa la noción de 'exceso' para explicar no solo la magnitud de la muerte violenta en Colombia sino para discutir lo excesivo de la carga simbólica de las muertes violentas. La 'escenificación' de la muerte violenta facilita el exceso simbólico. En esta relación entre escena y carga simbólica el ver/ser visto es característica del exceso. Siguiendo el argumento, podría decirse que si no hay espectáculo, visualización, acto público, no hay exceso. En ese sentido, la constante en la explicación hecha por Lena a la relación entre lo público y el 'chirretiarse'.

En este caso, interesa explorar la idea de exceso desde las categorías de sujetos que son objeto de amenaza y acción violenta, por ejemplo mediante los panfletos que se mencionaron. Como se señaló antes, el que las categorías de 
sujetos amenazados aparezcan en asociaciones sugiere que no es una condición de diferencia aislada la que se marca como objeto de este tipo de violencia sino la forma en que unas y otras son conectadas para dar una sensación de 'desorden', riesgo o amenaza a un determinado orden social, como se hace por ejemplo en el panfleto.

Esta lógica de 'ser peladas serias' y mostrar progreso opuesta al 'chirretiarse' y no mostrar exceso, es una experiencia del género y la sexualidad. Lo que Lena llamó en un momento la 'renovación del conflicto' y la forma como lo vive desde la interacción entre diversas condiciones de vulnerabilidad, requiere ser ubicado en un contexto más amplio en el cual actores armados han impuesto particulares regímenes de género y de sexualidad. A los ordenamientos de género mencionados antes, el que resulta de la migración laborar del interior del país a la costa y el que viene de las relaciones tradicionales de solidaridad y alianza familiar se suma otro, propiciado por el proyecto militar y político promovido por el paramilitarismo.

Investigaciones recientes encuentran que entre 1997 y 2005 miembros de las Autodefensas Unidas de Colombia establecieron un control despótico en la zona Caribe, usando una gama diversa de formas de violencia sexual y de género (CNRR, 2011). Representaciones autoritarias y humillantes del género, soportadas por un prolongado control de muchos aspectos de la vida cotidiana fueron fundamentales para su conquista territorial. La violencia contra homosexuales, en formas como el asesinato, la amenaza o la humillación pública fueron también parte de la imposición de ciertas nociones de feminidad y masculinidad (CNRR, 2011, p. 67). Este control correspondía a un proyecto militar y político orientado a producir todo un reordenamiento social, económico y político. Como han planteado algunos autores, se trataba de una 'refundación de la patria' (López, 2010).

La conexión entre el proyecto militar del paramilitarismo y sectores de la vida política nacional, creó lo que ha sido llamado la 'parapolítica'. Un modelo de gobernabilidad que combinaba la coerción privada violenta con la captura de recursos públicos, restricciones de la vida pública y alianzas entre élites sociales, económicas y políticas (Gutiérrez, 2010). La conexión entre las políticas sexuales y de género impuestas por actores armados y orientadas a regular de manera detallada las vidas de mujeres y hombres en las zonas en conflicto y como parte de las estrategias de guerra, bien puede llamarse como una 'para-política sexual'. 
Aunque no haya vivido en las zonas en guerra o en los momentos álgidos del conflicto, Lena también ha construido su experiencia juvenil, sexual y de género bajo las políticas promovidas por los actores armados en conflicto. $\mathrm{Su}$ historia pone en escena la forma como tal proyecto se incorporó en múltiples aspectos de la vida diaria tanto en las comunidades directamente afectadas como en aquellas zonas en apariencia 'fuera' de la guerra, como las ciudades capitales. Su descripción de la vida en la ciudad, si bien no es la de una de una zona de guerra si hace pensar en un cierto 'estado de sitio' permanente, cotidiano y sutil, pero no por ello menos impactante en la vida de determinados sectores sociales.

Sin embargo, la historia que cuenta Lena también relata la forma como desde la misma experiencia juvenil, sexual y de género se han dado respuestas y alternativas a esa incorporación de la violencia en los cuerpos y los cursos vitales. El mencionado informe de la Comisión Nacional de Reparación y Reconciliación (CNRR, 2011) refiere una variedad de formas en que individual y colectivamente las mujeres resistieron la violencia paramilitar. Algunas veces esos actos fueron solitarios o dispersos otros colectivos y organizados.

Lena da cuenta de estrategias en su historia vital y las conecta con un ejercicio de agenciamiento y luchas por la dignidad. Una de ellas es la habilidad para leer el contexto y poder balancear los riesgos. Así, la descripción anterior de evitar chirretiarse y el 'estar pilas' a lo que pasa alrededor se aplica tanto a su comportamiento de género como a su vida cotidiana. Una descripción similar en cuanto a la constante lectura de lo que sucede alrededor para determinar cuando los riesgos son imposibles de manejar fue expresada por mujeres trans entrevistadas para esta investigación. Una de ellas, que vivió por varios años en zonas directamente afectadas por el conflicto, describió una gama de estrategias mediante las cuales pudo montar su salón de belleza en tales zonas y lograr, temporalmente, una frágil protección. En una ocasión, ante la circulación de panfletos amenazantes, ella decidió hablar directamente con el jefe del grupo paramilitar del lugar. La confianza que demostró con ese hecho y la forma como manejó la conversación con el jefe paramilitar la hizo 'caer en gracia' y le permitió trabajar en la zona. Finalmente, si los actores armados determinan quien muere, también determinan quien vive y como. En su caso, 'evitar escándalos' y ser 'una mujer de su casa' fueron las garantías de protección. Tal permiso para estar, sin embargo no fue suficiente garantía cuando la presión de la comunidad se hizo evidente y ella decidió salir del lugar. Que tanto de resistencia o de sobrevivencia hay en estas estrategias 
requiere estudios posteriores en los cuales las propias personas implicadas puedan revisar y evaluar las posibilidades y restricciones a las que se vieron abocadas. Sin embargo, la consideración de las luchas por la dignidad requiere también ser integrada al análisis.

\section{Conclusión}

T a historia compartida por Lena reta las clasificaciones que separan unas violencias de otras y demandan derechos por separado. Implica también

un reto a las categorías fijas de sujetos definidas desde una condición de vulnerabilidad. Genera preguntas sobre lo que significa un escenario de postconflicto, cuando unas formas de violencia se transmutan y recomponen manteniendo para algunos sectores sociales el ser objeto permanente de violencia y la sensación de 'en cualquier momento me matan', con que Lena terminó su historia. A la vez, muestra las paradojas de una situación en la cual, ante demandas del mercado, las diferencias entre inclusión y exclusión no siempre son tan claras y las jerarquías sociales se recomponen.

En un contexto de apertura económica y de promoción de la región Caribe como polo de turismo nacional e internacional promueve ciertos cambios e impide otros. El bar donde Lena y su novia fueron expulsadas es a la vez promovido como destino del turismo internacional juvenil y alternativo. Con la llegada de turismo internacional nuevas formas de interacción sexual y de género circulan y conviven entre sí. Travestis en prostitución, por ejemplo, se desplazan a lo largo del año de un lugar a otro de la costa de acuerdo con las oleadas turísticas. Los estereotipos raciales sobre los hombres caribeños asociados a su masculinidad y comportamiento sexual generan un mercado homo y heterosexual que refuerza unos modos de relación y genera otros. Así, divisiones tradicionales entre 'cacorros' y 'locas' conviven con identidades 'gay modernas' ya no divididas por el rol sexual sino por su integración a culturas y mercados más globales. La región parece ofrecerle a unos lo que no le permite a otros.

Con la importancia del control y escrutinio social del género y la sexualidad, Lena también introdujo la importancia de las emociones. En su relato la experiencia de la violencia esta tanto corporizada como mediada por las emociones. Miedo y zozobra caracterizan la presencia constante de la violencia. Pero a la par, va la lucha por la dignidad. Al termino de la entrevista Lena mencionaba: 'yo no tengo porque vivir así. La dignidad no es negociable, no debería ser comprada. En nuestro caso, la dignidad es una línea delgada, un espacio claro-oscuro en el cual, hasta ahora, no hemos cruzado la línea'. Como 
hacer que la dignidad no sea una frágil línea sino una experiencia colectiva y sostenida debería ser una pregunta central en la noción de paz que se debate en Colombia actualmente.

\section{BIBLIOGRAFÍA}

ANTJIE, K., \& NOSISI, M. (2009). Archived voices: Refiguring three women's testimonies delivered to the South African truth and reconciliation commission. Tulsa studies in women's literature, 28(2), 357-374.

BEVERLY, J. (2000). Testimonio, subalternity, and narrative authority (N. K. Denzin \& Y. S. Lincoln, Trans.). In N. K. Denzin \& Y. S. Lincoln (Eds.), Handbook of qualitative research (2nd ed. ed., pp. 555-565). Thousand Oaks: Sage Publications.

BLAIR, E. (2005). Muertes violentas: La teatralización del exceso. Medellín: Universidad de Antioquia.

CNRR. (2011). Mujeres y guerra. Víctimas y resistentes en el Caribe colombiano. Bogotá: Distribuidora y Editora Aguilar, Altea, Taurus, Alfaguara.

CONNELL, R. (1987). Gender and power: society, the person and sexual politics. Sydney: Allen \& Unwin.

DAS, V. (2007). Life and words: Violence and the descent into the ordinary. Berkeley: University of California Press.

DI SILVIO, L. (2011). Correcting corrective rape: Carmichele and developing South Africa's affirmative obligations to prevent violence against women. Georgetown Law Journal, 99(5), 1469.

EPPRECHT, M. (2004). Hungochani: The history of a dissident sexuality in southern Africa. Montreal, Ithaca: McGill-Queen's University Press.

FRYKMAN, M. (2008). The forgotten majority on civilians' war experiences. Ethnologie Francaise, 38(2), 315-324.

FRYKMAN, M. P. (1997). Identities in war: Embodiments of violence and places of belonging. Ethnologia Europaea, 27(2), 153-162.

GUTIÉRREZ, F. (2010). Reflexiones a propósito del libro "Y refundaron la patria". In C. Lopez (Ed.), Y refundaron la patria. De como mafiosos y politicos refundaron el estado colombiano. Bogotá: Corporacion Nuevo Arco Iris, Congreso Visible, Dejusticia, Grupo Método, MOE.

HAUG, F. (1987). Female sexualization: A collective work of memory. London: Verso.

KIM, S. N. (2008). Whose voice is it anyway? Rethinking the oral history method in accounting research on race, ethnicity and gender. Critical Perspectives on Accounting, 19(8), 1346-1369.

No. 15. Agosto de 2015 Palobra 
KLEINMAN, A.; DAS, V. \& LOCK, M. M. (Eds.). (1997). Social suffering. Berkeley: University of California Press.

LÓPEZ, C. (2010). Y refundaron la patria. De como mafiosos y politicos refundaron el Estado colombiano. Bogotá: Corporación Nuevo Arco Iris, Congreso Visible, Dejusticia, Grupo Método, MOE.

NORDSTROM, C. (1999). Wars and invisible girls, shadow industries, and the politics of notknowing. International Feminist Journal of Politics, 1(1), 14-33.

ORDÓÑEZ, J. P. (1996). No human being is disposable: Social cleansing, human rights and sexual orientation in Colombia (pp. 48). Washington: International Gay and Lesbian Human Rights Commision, Colombia Human Rights Committee, Proyecto Dignidad.

PANKHURST, D. (2008). Post-War backlask violence against women. What can "Masculinity" Explain? In D. Pankhurst (Ed.), Gendered peace: women's struggles for post-war justice and reconciliation (pp. 293-320). New York: Routledge.

PRADA, N.; GALVIS, S.; LOZANO, L. \& ORTIZ, A. (2012). A mi me sacaron volada de allá. Relatos de vida de mujeres trans desplazadas forzosamente hacia Bogotá. Bogotá: Universidad Nacional de Colombia, ACAC.

ROJAS, C. (1994). La violencia llamada "limpieza social". Bogotá: Cinep.

SERRANO-AMAYA, J. F. (2004). Menos querer más de la vida. Concepciones devVida y muerte en jóvenes urbanos. Bogotá: Universidad Central, Siglo del Hombre Editores.

SMELSER, N. J. \& ERIKSON, E. H. (1980). Themes of work and love in adulthood (N. J. Smelser \& E. H. Erikson, Trans.). Cambridge: Harvard University Press. 

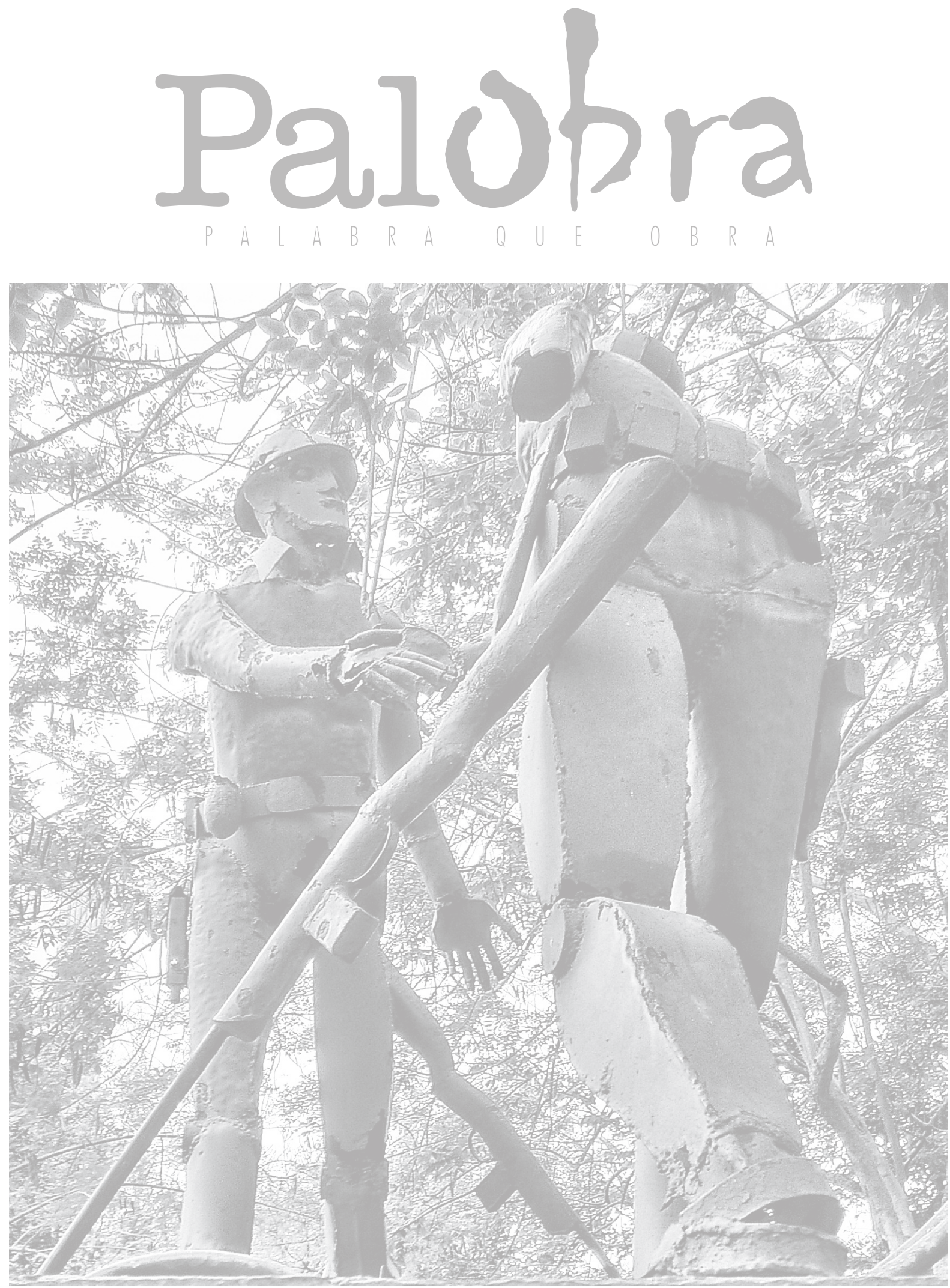

Foto: Sullay Torres Sánchez 